teaching embodied in Humanae Vitae and subsequent encyclicals as a source of psychological harm that may occasionally have physical consequences, for example where a patient is reluctant to seek advice and treatment until it is too late for effective therapy. She recognises that the ban on the Pill is widely ignored by Catholics, and that Catholic women seeking an abortion will go into the back streets or travel abroad to obtain one if there is no alternative, but she does not underrate the damage to individuals and families caused by a persisting sense of guilt.

If The Harm We Do was merely an attack on a dogmatic theological position that the author considers doubtfully tenable it would be of limited interest outside the rather narrow circles of moral theologians and interpreters of the teaching of the central hierarchy of the Roman Church. It is, however, much more than this, in two respects. First, Dr Poole makes plain the strength of her own Christian belief, grounded in the theology of the Second Vatican Council, which laid great emphasis on the duty of all believers to bring their knowledge and experience to bear on the search for right and true judgments of conscience. Her critique does not spring from anger, but from a concern that what the Roman Church has to say on spiritual matters of central importance is becoming increasingly obscured by inappropriate moral pronouncements on non-essential issues of sexual and medical ethics that endanger its credibility and marginalize many loyal and committed Catholics.

Secondly, and more generally, her book is an autobiographical account of a life spent in the practice of medicine that is a model for all young doctors and other health care professionals. At a time when counselling is talked about as if it was something quite new in medicine, in the context of genetic screening for instance, it is refreshing to be reminded that listening to patients and exploring therapeutic options with them is central to good clinical practice, and not an add-on extra. Dr Poole's warm and straightforward way of writing is enjoyable to read, and her book deserves wide commendation in medical schools.

CAROLINE MILES Member, Nuffield Council on Bioethics and formerly Ian Ramsey Fellow, St Cross College, Oxford
Challenges in medical care

Edited by Andrew Grubb, Chichester, John Wiley and Sons, 1992, 196 pages, $£ 25.00$ hc

This latest offering from the Centre of Medical Law and Ethics at King's College, London, makes fascinating reading. The scope of the collection is wide, drawing in contributions from philosophers, lawyers, sociologists, archbishops, and even doctors. This is a healthy sign; medical ethics, perhaps uniquely among the branches of applied philosophy, is a broad church, in which there is room for the perspectives of many disciplines.

It is invidious, but inevitable, to select from a fine collection of this nature, but two essays are of particular interest. Jenifer Wilson Barnett, who is a professor of nursing studies, writes on inequality among health care professionals and on the ethical dimensions of their relationship. She questions the myth of team-work, which too often is something to which mere lip service is paid. Nurses are consulted, but not necessarily listened to; nurses are not informed of the reasons for decisions which they will be implementing; the catalogue of concerns is, it would appear, fairly long. Greater equality, she argues, involves greater respect, and leads to better nursing of the patient. These goals are now increasingly acknowledged, but it would seem that we have some way to go before they are achieved.

Ian Kennedy and Andrew Grubb, in their joint essay on HIV, AIDS and human rights, also concern themselves with equality. The theoretical commitment which our society has to a non-censorious approach to the ill is not matched by a practical outlawing of discriminatory practices. Kennedy and Grubb demonstrate that in a range of areas the law fails to provide those who are HIV-positive or suffering from AIDS with any real degree of protection against discriminatory treatment. This is so in the area of employment law, where HIV-positive employees have less than full protection against dismissal as a result of the concern of other employees or customers, and it is also so, in very marked form, in relation to insurance. It must be accepted that insurance is a business, legitimately concerned with profit, but it is also all about risksharing, and one might have thought that this is a classic case where risk should be shared. If AIDS is going to result in increased expenditure from the insurance industry - as it undoubtedly will - then this could surely be spread through generally increased premiums. The commercial justification for discriminatory practices, including the controversial refusal of insurance where negative test results have been obtained, should then fall away. Also at stake, as the authors stress, are issues of privacy. The 'life-style' question is intrusive, too broad-brush, and gives rise to real ethical concern. Certain other countries have been very much more assiduous in their protection of the rights of those afflicted by this condition. We lag behind - again. The reasons for this are complex, but are not unconnected with difficulties we have in the United Kingdom with reform in the area of individual human rights. The constitutional reform which that requires seems, for some reason, simply not to be on the agenda.

ALEXANDER MCCALL SMITH Department of Private Law, University of Edinburgh, Old College, South Bridge, Edinburgh EH8 9YL

\section{Law reform and human reproduction}

\author{
Edited by Sheila McLean, \\ Dartmouth, Dartmouth Publishing \\ Group, 1992, 323 pages, $£ 35.00 \mathrm{hc}$
}

'Another book on human reproduction', one might be pardoned for sighing. Yet, but. In this collection, Sheila McLean has brought together an astonishingly broad range of authors from a large number of countries to write about national experience in this area of law reform. This makes the book different, and worthwhile, bearing in mind the difficulties of obtaining material on the way in which the task of dealing with the new reproductive techniques has been dealt with elsewhere.

There are contributions from Canada, Australia, New Zealand, France, the United Kingdom, and (the former) Czechoslovakia. There is no contribution from Germany, which is an omission, given the very particular nature of the debate on such questions there. It would also have been useful to compare the guilt-affected German 